
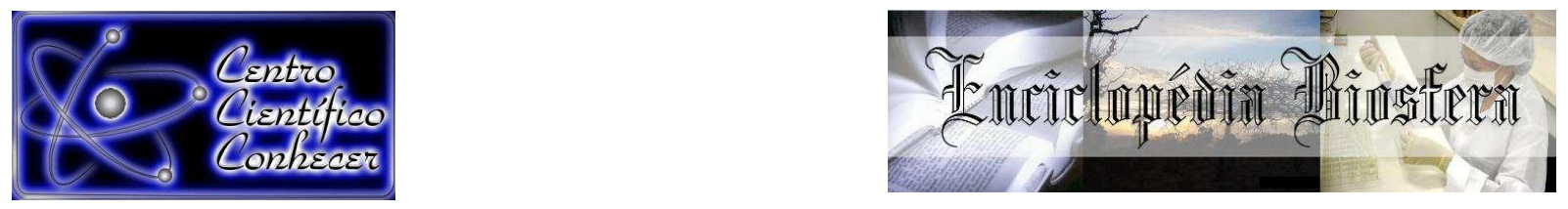

\title{
EFEITO DE DIFERENTES CONCENTRAÇÕES DE SAIS E BAP NA BROTAÇÃO IN VITRO DE PATAQUEIRA
}

Diene Xavier Araújo', Ana Paula Ribeiro Medeiros ${ }^{2}$, Rafael Marlon Alves de Assis ${ }^{1}$, Fernanda Naiara Santos Ribeiro ${ }^{2}$, Osmar Alves Lameira ${ }^{3}$

${ }^{1}$ Mestrando no Programa de Pós-Graduação em Plantas Medicinais, Aromáticas e Condimentares, Universidade Federal de Lavras, 37.200-000, Lavras-Minas Gerais, Brasil

${ }^{2}$ Doutoranda no Programa de Pós-Graduação em Plantas Medicinais, Aromáticas e Condimentares, Universidade Federal de Lavras paula.amedeiros@hotmail.com, 37.200-000, Lavras-Minas Gerais, Brasil

${ }^{3}$ Pesquisador Doutor, Embrapa Amazônia Oriental, Belém-Brasil

Recebido em: 02/10/2017 - Aprovado em: 21/11/2017 - Publicado em: 05/12/2017 DOI: 10.18677/EnciBio_2017B29

\section{RESUMO}

Conobea scoparioides Cham. \& Schltdl é uma espécie vegetal utilizada na medicina popular caseira no combate de cáries e béri-béri pela população. A extração do seu óleo essencial é a principal motivação de interesse econômico nas indústrias cosmética e farmacológica. O cultivo in vitro é uma das possíveis ferramentas utilizadas para a multiplicação dessa espécie em larga escala em um curto intervalo de tempo. Objetivou-se avaliar o efeito de concentrações de sais na composição do meio MS e BAP em função do tempo após a inoculação, afim de aperfeiçoar os procedimentos técnicos da multiplicação in vitro de pataqueira. O estudo foi realizado na Embrapa Amazônia Oriental, Belém-Pa. Foram utilizados explantes de plântulas préestabelecidas in vitro de pataqueira inoculados em meio MS (1/4MS, $1 / 2 \mathrm{MS}$ e $1 \mathrm{MS})$, combinadas com BAP (0 e 2 mg. $\mathrm{L}^{-1}$ ) em três tempos após a inoculação $(10,20,30$ dias). O experimento foi inteiramente casualizado em esquema fatorial $6 \times 3 \mathrm{com} 4$ repetições com três frascos cada. Foram avaliados o número médio de brotações e o comprimento médio dos brotos. Houve efeito significativo na interação de MS combinadas com BAP em relação ao número e comprimento de brotos de pataqueira. Os meios suplementados com BAP induziu um número maior de brotações, sendo que o período de avaliação aos 30 dias foi o único que mostrou interação entre as concentrações MS e do BAP. Assim, a combinação do MS com BAP no período de 30 dias promove maior brotações e crescimento in vitro de pataqueira.

PALAVRAS-CHAVE: BAP, Conobea scoparioides, cultura de tecido. 


\title{
EFFECT OF DIFFERENT SALT AND BAP CONCENTRATIONS IN IN VITRO SHOOT INDUCTION OF PATAQUEIRA
}

\begin{abstract}
Conobea scoparioides Cham. \& Schltdl is a plant species used in popular traditional medicine against tooth decay and beriberi. Its essential oil extraction is the main economic interest motivation for cosmetic and pharmacological industries; the in vitro culture is one of the possible tools applied in the large-scale multiplication within short time periods. Thus, this work aimed to evaluate the effect of salt and BAP concentrations in MS medium over the time after inoculation, in order to optimize the in vitro multiplication technical procedures of pataqueira. The study was carried out in the Embrapa Eastern Amazon, Belém-PA. In vitro pre-established pataqueira plantlets were used as explants, which were inoculated in MS medium ( $1 / 4 \mathrm{MS}, 1 / 2 \mathrm{MS}$ and $1 \mathrm{MS}$ ), combined with BAP (0 and 2 mg.L-1) in three periods after inoculation (10, 20 and 30 days). The experimental design was the completely randomized design in factorial scheme of $6 \times 3$ with 4 replications with 3 flasks each. It was evaluated the mean shoot number and mean shoot length. There was significant effect in the interaction of MS with BAP related to the number and length of pataqueira shoots. The BAP-supplemented media induced higher shoot number, being the 30-day period the only one to show interaction between MS and BAP concentrations. Therefore, the combination of MS with BAP in the 30-day period promotes higher shoots and in vitro growth of pataqueira.
\end{abstract}

KEYWORDS: BAP, Conobea scoparioides, tissue culture.

\section{INTRODUÇÃO}

Conobea scoparioides Cham. \& Schltdl. (Scrophulariaceae) é uma espécie herbácea, popularmente denominada de pataqueira ou vassourinha-do-brejo, é uma planta muito aromática, característica do norte brasileiro, sendo que a população nativa utiliza esse vegetal para banhos de cheiro e para o tratamento do beribéri. Essa espécie é encontrada em áreas semi-inundadas, terras baixas, rios e riachos. Apresenta um rendimento em óleo essencial de 1,5 a $3,0 \%$ e os principais componentes do seu óleo são: $\alpha$-felandreno, metiltimol e timol. O óleo essencial de pataqueira possui uma alta capacidade antioxidante e importante atividade biológica (MAIA, 2007; REBELO et al., 2009).

Estudos realizados por Oliveira (2015) relatam que a C. scoparioides se propaga naturalmente através de sementes (sexuada) e por estacas (assexuada) de ramos de 10 a $15 \mathrm{~cm}$ de comprimento com 2 a 3 nós, em locais bem irrigados, a pleno sol, de preferência no início do inverno, que na região Norte ocorre nos meses de dezembro e janeiro. Entre as características mais marcantes dessa espécie, destacam-se os constituintes timol, metiltimol e a-felandreno, presentes no óleo essencial da espécie, que expelem odores agradáveis (COSTA et al., 2014), os quais são de interesse para o mercado brasileiro de perfumes e cosméticos (OLIVEIRA, 2015).

Segundo Moraes et al. (2012), a técnica de cultura de tecidos vegetais é amplamente usada para produção em escala industrial de espécies que servirão como fonte de compostos biologicamente ativos e aprimoramento da produção de fitofármacos, a fim de assegurar exploração sustentável das espécies. Dalga (2012) 
afirma que é fundamental o conhecimento da biologia da planta, uma vez que cada espécie tem necessidades diferentes e, portanto, distintos padrões de crescimento e desenvolvimento. Um dos principais fatores que interferem na propagação in vitro é a suplementação do meio de cultivo com reguladores de crescimento vegetal. As citocininas são uma classe de reguladores com capacidade marcante de induzir a divisão celular em tecidos vegetais. Portanto, são importantes para formação de órgãos, principalmente aéreos. A benzilaminopurina (BAP) é uma citocinina sintética utilizada para a multiplicação in vitro de diversas espécies (LUCAS et al., 2007).

Nesse sentido, o estudo teve como objetivo avaliar o efeito de diferentes concentrações de sais na composição do meio líquido MS combinado ao regulador de crescimento, BAP (6-benzilaminopurina), sobre a multiplicação de brotos de $C$. scoparioides.

\section{MATERIAL E MÉTODOS}

\section{Material vegetal}

O trabalho foi realizado no Laboratório de Biotecnologia da Embrapa Amazônia Oriental. Para a obtenção de explantes foram utilizadas plantas de C. scoparioides, previamente cultivadas em meio de cultura MS (MURASHIGE; SKOOG,1962).

\section{Preparação do meio de Cultura}

Os tratamentos do experimento foram constituídos por diferentes concentrações de sais no meio de cultura MS, adicionadas de diferentes doses do regulador de crescimento 6-Benzilaminopurina (BAP). Para a formulação dos meios de cultura utilizou-se três concentrações de sais na composição do meio MS: um quarto (1/4MS), a metade $(1 / 2 \mathrm{MS})$ e a concentração completa (1MS) dos sais do meio MS combinadas com as concentrações de 0 e $2 \mathrm{mg}^{-\mathrm{L}^{-1}}$ de BAP ( Tabela 1). Os meios de cultura foram suplementados com $3 \%$ de sacarose, solidificados com phytagel a $0,3 \%, 0 \mathrm{pH}$ foi ajustado para 5.8 e posteriormente autoclavados a $120^{\circ} \mathrm{C}$ durante 20 minutos.

TABELA 1- Concentrações de sais no meio de cultura MS, com diferentes doses de citocinina (BAP). Belém, PA, 2015.

\begin{tabular}{cc}
\hline Concentração de sais (MS) & BAP mg.L-1 \\
\hline MS & \\
MS $1 / 2$ & $0 \mathrm{mg} \cdot \mathrm{L}^{-1} 2 \mathrm{mg} \cdot \mathrm{L}^{-1}$ \\
$\mathrm{MS}^{1 / 4}$ & \\
\hline
\end{tabular}

\section{Inoculação em meio de cultura}

As plantas foram repicadas retirando-se os segmentos nodais com de cerca de $1 \mathrm{~cm}$ de comprimento. Em seguida, os explantes obtidos foram inoculados na posição vertical em frascos $(250 \mathrm{~mL})$ contendo o meio $\mathrm{MS}$ com as proporções pré-estabelecidas de sais e de BAP (Figura 1), esse processo foi realizado sob condições assépticas em câmara de fluxo laminar vertical. Após a inoculação dos explantes, os frascos foram acondicionados em sala de crescimento sob fotoperíodo de $16 \mathrm{~h}$ luz $\mathrm{dia}^{-1} \mathrm{com}$ 
intensidade luminosa de $25 \mu \mathrm{mol} . \mathrm{m}^{2} . \mathrm{s}^{-1}$ de irradiância e temperatura de $25 \pm 3^{\circ} \mathrm{C}$. Foi avaliado o número médio de brotações e comprimento médio dos brotos.

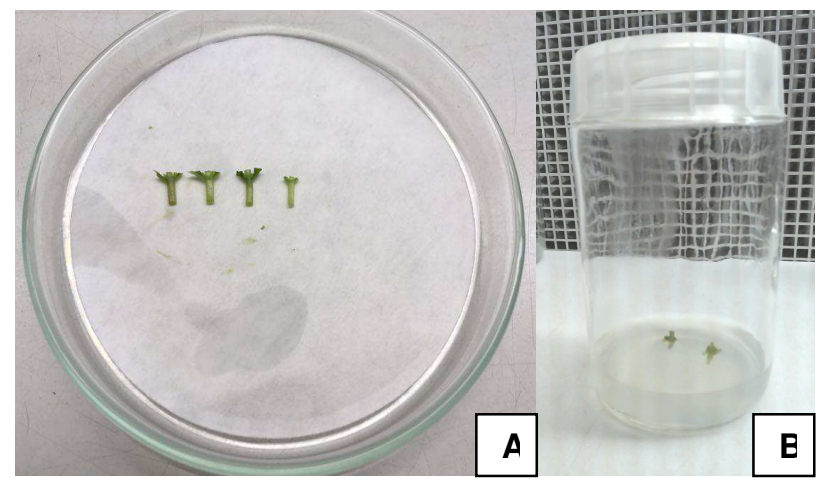

FIGURA 1- A: Explantes dos segmentos nodais de C. scoparioides com de cerca de $1 \mathrm{~cm}$ de comprimento. B: Inoculação dos explantes na posição vertical em frascos $(250 \mathrm{~mL})$ contendo o meio MS.

\section{Análise estatística}

O experimento foi conduzido em DIC (Delineamento Inteiramente Casualizado), em arranjo fatorial 6 (concentrações de sais no meio de cultura MS +BAP) x 3 (períodos de inoculação-10, 20 e 30 dias), com 4 repetições com três frascos cada, contendo dois explantes por frasco. A análise de variância foi feita pelo programa estatístico Sisvar e a comparação de média pelo teste Scott-Knott a 5\% de probabilidade.

\section{RESULTADOS E DISCUSSÃO}

Em relação ao número de brotos de $C$. scoparioides apresentados na Figura 2, houve efeito significativo para a interação das diferentes concentrações de sais com BAP em relação aos diferentes períodos de avaliação (dias) $(P<0,05)$. Assim, a aplicação de sais MS e do BAP juntos, nas concentrações testadas, proporcionaram aumento significativo na indução de brotações em relação aos submetidos ao tratamento com meio MS líquido sem BAP, sendo que o período de avaliação aos 30 dias foi o mais expressivo entre as interação de MS e BAP.

Para as concentrações de sais e BAP $\left(\mathrm{mg} \mathrm{L}^{-1}\right)$ utilizados, o número de brotos induzidos pela concentração "MS + 2 de BAP e MS 1/4 + 2 de BAP" foi estatisticamente superior número de brotos induzidos pelas demais concentrações. Sendo a concentração 1/4 + 2 de BAP a qual apresentou maior número médio (15) de brotos aos 30 dias do período de avaliação, verificando-se assim que a presença de BAP no meio de cultivo favorece o acréscimo de broto e o meio nutritivo sem BAP foi considerado ineficiente.

No trabalho de propagação in vitro de Lippia integrifólia realizado por Lannicelli et al. (2016), os tratamentos com BAP no meio de cultura, promoveram maior produção indução de brotos, levando-se em consideração que esse regulador de crescimento 
está diretamente ligado a uma alta taxa de multiplicação de brotos. É o que pode ser observado em trabalhos de propagação de cultura in vitro com Justicia pectoralis, Croton cajucara Benth e Oncidium baueri Lindl. (FREITAS et al., 2016; SILVA et al., 2015; RODRIGUES et al., 2016). Demostrando assim que o presente trabalho obteve o mesmo comportamento em relação à produção de brotos de $C$. scoparioides cultivada in vitro.

Em relação aos períodos de avaliação, pode-se observar que o explante obteve maior número de brotação aos 30 dias após a repicagem, sendo os avaliados no período de 10 e 20 dias estatisticamente iguais. De acordo com Santos et al. (2016) no trabalho realizado com diferentes concentrações de BAP, aos 30 dias do cultivo in vitro de Etlingera elatior teve grande variação na quantidade de brotos de acordo com cada concentração de BAP, provavelmente pelo fato da cultura ainda estar se adaptando às novas condições de cultivo. No caso do experimento da $C$. scoparioides teve uma quantidade de brotação uniforme no inicio se diferenciando ao longo do tempo demostrando assim a eficiência e a importância de se utilizar o BAP no meio de cultivo dessa espécie para produção de brotos.

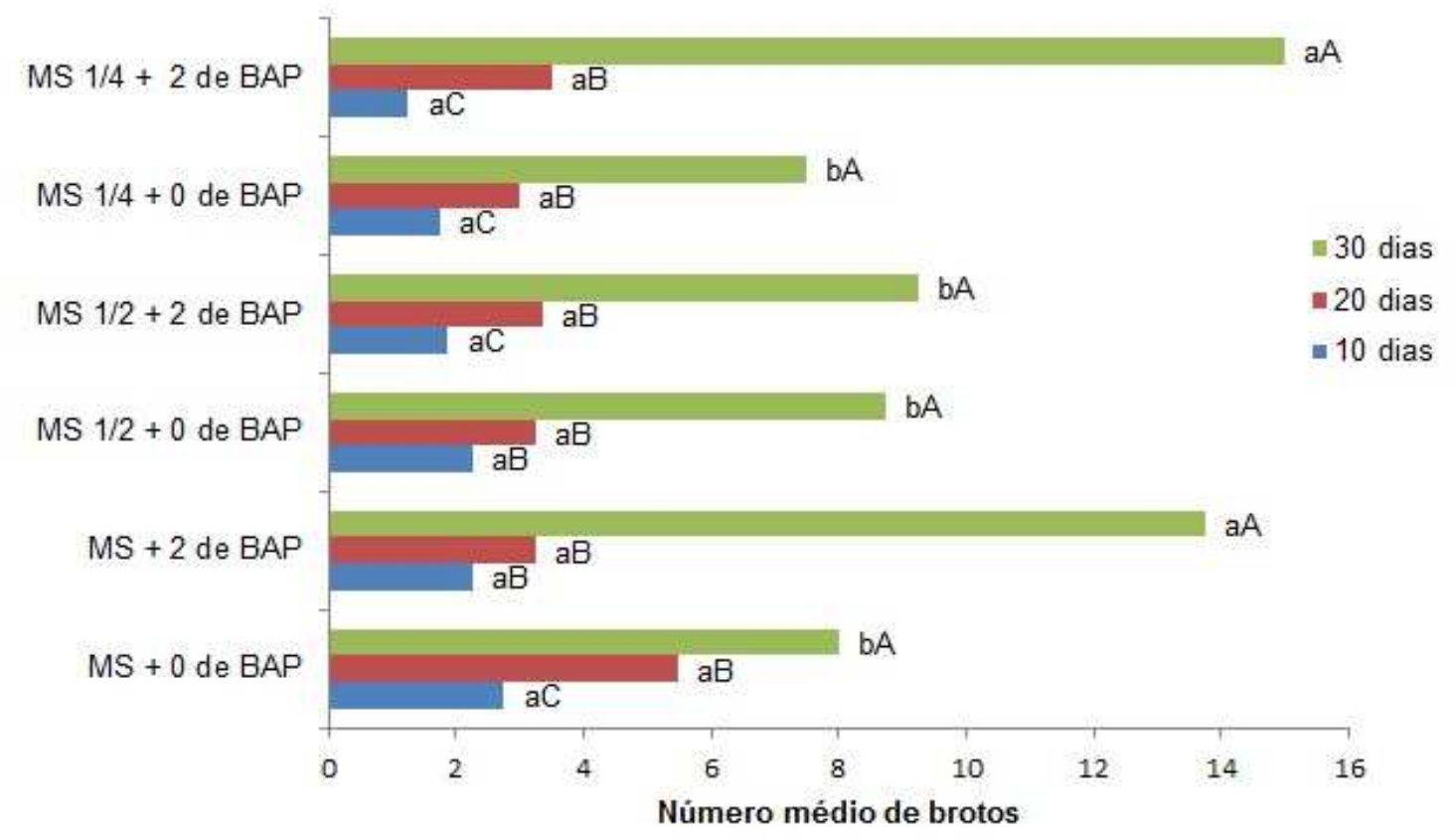

FIGURA 2- Número médio de brotos de $C$. scoparioides obtidos em meio MS suplementado com BAP após três períodos de inoculação. Barras seguidas pelas mesmas letras minúscula entre os meios MS (para o mesmo período) e maiúscula dentro de cada meio MS (entre os períodos) não diferem entre si pelo teste de scott-Knott a $5 \%$ de probabilidade. Fonte: Autores (2017)

Observou-se o crescimento médio dos brotos de $C$. scoparioides em todos os tratamentos, considerando de maneira geral que a adição de citocinina (BAP) ao meio nutritivo reduziu o crescimento dos brotos. Como exemplo é possível verificar para o período de 30 dias, a redução de $7,50 \mathrm{~cm}$ quando foi utilizado MS $1 / 4+0$ de BAP no 
crescimento do broto para $1,25 \mathrm{~cm}$ quando utilizado o meio nutritivo MS $1 / 4+2$ de BAP (Figura 3).

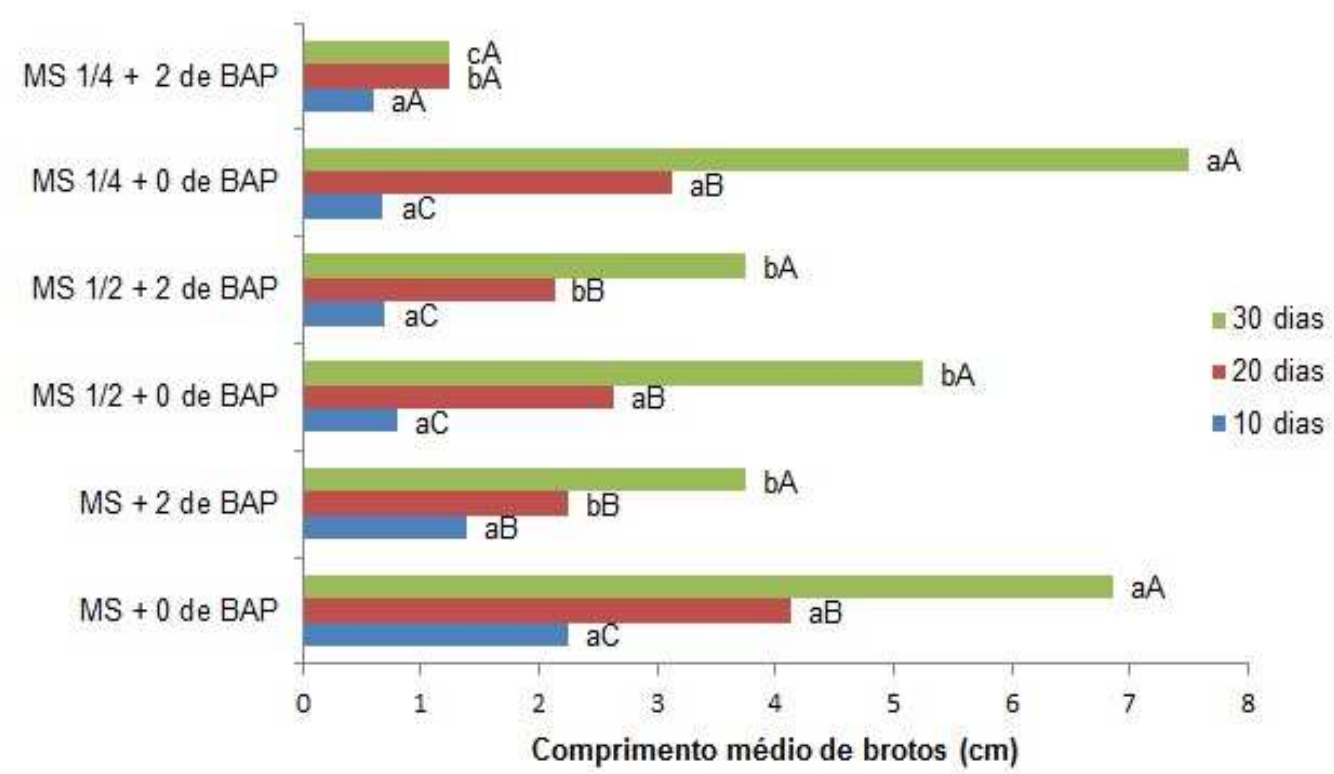

FIGURA 3- Comprimento médio de brotos de $C$. scoparioides obtidos em meio MS suplementado com BAP após três períodos de inoculação. Barras seguidas pelas mesmas letras minúscula entre os meios MS (para o mesmo período) e maiúscula dentro de cada meio MS (entre os períodos) não diferem entre si pelo teste de scott-Knott a $5 \%$ de probabilidade. Fonte: Autores (2017).

Com relação aos períodos de avaliação, verificou-se que o comprimento médio $(\mathrm{cm})$ dos brotos de $C$. scoparioides apresentaram diferença estatística, com acréscimo significativo de maneira geral do período de 10 dias à 30 dias, o que sugere um representativo crescimento para formação de mudas. Resultado semelhante foi obtido por Dias et al. (2011), trabalhando com Ananas comosus var. ananassoides (L.) Merr. (Baker) Coppens \& F. Leal, conhecida popularmente como abacaxizeiro, obtiveram maior crescimento $(\mathrm{cm})$ de brotos na ausência de BAP, considerando que o aumento nas concentrações desta citocinina reduziu significativamente o comprimento dos brotos. O favorecimento para o aumento do número de brotos e o retardo do crescimento de brotos de $C$. scoparioides corrobora a ação natural da citocinina, que estimula a divisão celular e reduz a dominância apical. Segundo Taiz e Zeiger (2004) a dominância apical é determinada pela auxina, sendo a citocinina atuante no início do crescimento das gemas laterais.

\section{CONCLUSÕES}

O meio de cultura suplementado com citocinina (BAP) promoveu maior efeito sobre a brotação de pataqueira e a ausência dessa citocinina teve maior efeito no crescimento para os períodos avaliados, sendo o período de 30 dias o mais eficiente. 
Desse modo a suplementação é favorável para a multiplicação in vitro da espécie estudada.

\section{REFERÊNCIAS}

DAGLA, H. R. Plant Tissue Culture: Historical Developments and Applied Aspects. Resonance, v. 17, n.08, p.759-767, 2012. Disponível em: <http://goo.gl/k5IPJa>. doi: $10.1007 / \mathrm{s} 12045-012-0086-8$

DIAS, M. M.; PASQUAL, M.; ARAÚJO, A. G.; SANTOS, V. A. Reguladores de crescimento na propagação in vitro de abacaxizeiro ornamental. Revista Brasileira de Ciências Agrárias, v.6, n.3, p.383-390, 2011. Disponível em: < http://www.agraria.pro.br/sistema/index.php?journal=agraria\&page=article\&op=viewArtic le\&path\%5B\%5D=agraria_v6i3a818>. doi: 10.5039/agraria.v6i3a818

FREITAS, R. M. O.; NOGUEIRA, W. N.; PRAXEDES, S C. Multiplicação de anador (Justicia pectoralis) in vitro. Revista Verde de Agroecologia e Desenvolvimento Sustentável, v.11, n.3, p.159-163, 2016. Disponivel em: < http://www.gvaa.com.br/revista/index.php/RVADS/article/view/3986/3807>. doi: http://dx.doi.org/10.18378/rvads.v11i3.3986

LANNICELLI, J.; TORRE, M. P. L.; COVIELLA, A.; AGUIRRE, E. D. V.; Elechosa, M. A.; BAREN, C. M.; PACHECO, M. G.; ESCANDÓN A. S. In vitro propagation of Lippia integrifolia (Griseb.) Hier. and detection of genetic instability through ISSR markers of in vitro-cultured plants. Revista de la Facultad de Agronomía, v.115, n.1, p.67-76, 2016. Disponível em: < http://hdl.handle.net/10915/54170 >.

LUCAS, M. A. K. LUCAS, FAGUNDES, J. D.; PEREIRA, D. D.; SARMENTO, M. B. Micropropagação de violeta-africana (Saintpaulia ionantha Wendl.): efeito da benzilaminopurina na multiplicação. Ciência e Agrotecnologia, v.31, n.5, p.1380-5, 2007. Disponível em: <http://www.scielo.br/scielo.php?pid=S141370542007000500016\&script=sci_abstract\&tlng=pt>. doi: dx.doi.org/10.1590/S141370542007000500016.

MORAIS, T.P.; LUZ, J.M.Q.; SILVA, S.M.; RESENDE, R.F.; SILVA, A.S. Aplicações da cultura de tecidos em plantas medicinais. Revista Brasileira de Plantas Medicinais, v.14, n.1, p.110-121, 2012. Disponível em <http://dx.doi.org/10.1590/S151605722012000100016>. doi: 10.1590/S1516-05722012000100016

MURASHIGE, T.; SKOOG, F. A revised medium for rapid growth and bioassays with tobacco tissue cultures. Physiologia Plantarum, v. 15, n. 3, p. 473-97, 1962. Disponível em: $\quad<\quad$ http://onlinelibrary.wiley.com/doi/10.1111/j.13993054.1962.tb08052.x/abstract>. doi: 10.1111/j.1399-3054.1962.tb08052.x

OLIVEIRA, D. Manual ilustrado: Pataqueira. 1.ed. : NATURA COPYRIGHT, 2015. $29 p$. 
REBELO, M. M.; SILVA, J. K. R.; ANDRADE E. H. A.; MAIA, J. G. S. Antioxidant Capacity and Biological Activity of Essential Oil and Methanol Extract of Conobea scoparioides (Cham. \& Schltdl.) Benth. Journal of the Brazilian Chemical Society, v. 20, n.6, 2009. Disponível em: < http://dx.doi.org/10.1590/S010350532009000600005 >. doi: $10.1590 /$ S010350532009000600005

RODRIGUES, D. B.; NADAL, C. M.; CAMARGO, S. S.; ASSIS, A. M.; SCHUCH, M. W.; PEIL, R. M. N.; FARIA, R. T. Growth regulators and substrates for Oncidium baueri Lindl. Micropropagation. Ciências Agrárias, v.37, n.5, p.2901-2910, 2016. Disponível em:< http://www.uel.br/revistas/uel/index.php/semagrarias/article/view/22291/19744>. doi: 10.5433/1679-0359.2016v37n5p2901

SANTOS, E. O.; RODRIGUES, A. A. SIlvA, E. R.; CARVALHO, A. C. P. P. Multiplicação de bastão-do-imperador em resposta a concentrações de BAP e número de subcultivos. Ornamental Horticulture, v.22, n.1, p.88-93, 2016. Disponível em< https://ornamentalhorticulture.emnuvens.com.br/rbho/article/view/826/632>.doi: http://dx. doi.org/10.14295/oh.v22i1.826

SILVA, T. L.; PEREIRA, M. A. A.; PEREIRA, J. E. S. Propagação in vitro de sacaca (Croton cajucara Benth.): entendimentos sobre a dificuldade no desenvolvimento de protocolos de micropropagação da espécie. Biotemas, v.28, n.4, p.41-50, 2015. Disponível em: < http://dx.doi.org/10.5007/2175-7925.2015v28n4p41>. doi: 10.5039/agraria.v6i3a818

TAIZ, L.; ZEIGER, E. Fisiologia vegetal, 3 ed. Porto Alegre: Artmed. 2004. 719p. 